\title{
AN INTRODUCTION TO THIS VOLUME
}

The East Asia region has drawn global attention. China, Japan, the Korean Peninsula and the ASEAN countries have been developing their economies and strengthening their participation in the global economy. Contrary to this smooth process, the region possesses a number of unresolved territorial issues and suffers from a lack of a security complex.

The volume presents a series of papers dedicated to the East Asian countries' development. The volume is divided into three sections: dimensions of regionalism in East Asia, China's external and internal development and Japanese domestic affairs. The first part is initiated by Roger Chao of Hong Kong University and presents the perspectives and realities on East Asian regionalism. In this region economic regionalism is highly developed, while other key components, especially the regional political and security framework, are stagnating and even regressing. These questions were raised in the second paper by Anna Walkowiak of Warsaw University, who mainly focuses on the regional insecurity complex in Northeast Asia. The key problem in this region seems to be linked to the nuclear ambitions of Pyongyang as well as the intentions of the two major players in the region, that is China and Japan. Joanna Dobkowska shows the relationship between Australia and Japan as a key issue in balancing China's rising power. This paper argues that Australia and Japan, taking a cooperative approach, are able to successfully re-shape the regional security architecture in the Asia-Pacific. Contrary to the hard security issues Marta Kosmala-Kozłowska, from Warsaw University, offers an issue on human rights within the ASEAN countries framework. The paper touches upon the important issue of culture and institutional frameworks for ensuring and securing basic human needs. Pawel Raja, a young scholar from Wroclaw presents the cultural issues regarding institutions in a Muslim country - Malaysia. He mainly introduces factors that forced the government to make institutional changes and improvements. In the second part we present China's internal and external development. China, as some say, will be the superpower of this century. Kao Pei-shan from Chiao Tung University presents the Sino-U.S. relationship via the concept of interdependence. She offers insights on trade relationship as a key factor in bilateral relations. Next, Michal Lubina from the Jagiellonian University touches upon the issue of Burma in China's foreign policy. 
He describes the history of their mutual relationship as well as China's goals in coping with the government in Rangun. China's activities have gone far beyond the Asian region. Interesting views are presented by academics from the University of Economy in Bratislava. The first paper, by Nora Szikorova, presents recent trends in the Middle Kingdom's policy towards Africa. Martin Grancay analyses the new rising problem within the relationship between China and the European Union: avionation. The last three papers in this section present China's domestic affairs. Yang Long and Hu Huixuan from Nankai University in Tianjin offer a unique perspective on the needs for the adjustment of regional development in the era of reform. Dominik Mierzejewski from the University of Lodz shows the difficulties in the transition of power inside the Communist Party of China. He points out the basic issues of economic development linked to the inflation rate and intra-party democracy as a concept that might secure the peaceful transition of power. Magdalena Senderowska from Warsaw School of Economics presents the food security problem in Mainland China as one of the most important for China's future development. In the last section that is dedicated to the Japanese domestic sphere four scholars offer their insights. Karol Żakowski from the University of Lodz presents a paper on the political scene in Japan and the new tendencies in shaping a "third pole" in the Japanese political system. Atsushi Tanaka (Kwansei Gakuin University) describes, in details, the monetary system in Japan as a matter of both economic development and political issue. Masahiro Yamada (Kwansei Gakuin University) describes the mechanisms of the 2009 Japanese Lower House Election. He offers a clear-cut perspective on the Japanese voters' perception. Finally, Tetsukazu Okamoto of Kansai University analyses the impact of social media, such as Twitter, on the behaviour of Local Political Candidates. He presents his case study based on the Osaka Prefectural Assembly Election.

This volume, published by the East Asia Studies Department of the Faculty of International and Political Studies at the University of Lodz, is the first of its kind for the department. In this regard the Editor poses great concerns about the new initiative, as well as a great hope that, as the Chinese saying goes: a journey of a thousand miles begins with a single step. 